\title{
8
}

\section{Emergency Placements: Human Rights Limits and Lessons}

\section{Elisabeth Gording-Stang}

\section{Introduction}

Children living in situations of risk because of violence, severe drug abuse, sexual abuse or other forms of serious neglect from their care persons depend on an efficient public system of emergency intervention to safeguard their right to care and protection. The administrative, legal and practical design of such an emergency system differs between countries. The thresholds of intervention might differ as well. Most Western countries have established some kind of emergency institution, although a variety of organizational affiliations of emergency bodies are possible (see e.g. Gilbert et al. 2011). Most common are the social welfare services/ Child Protection Services (CPS), the police or a combination of those two institutions.

Safeguarding the rights of children in emergency situations is an obligation that follows from the UN Convention on the Rights of the

E. Gording-Stang, LL.D. ( $ه)$

Department of Social Work, Child Welfare and Social Policy, Oslo

Metropolitan University, Oslo, Norway

e-mail: elisst@oslomet.no 
Child (CRC) Article 19 and the European Convention of Human Rights (ECHR) Articles 3 and 8, (Gilbert et al. 2011; see Sandberg, Chap. 2 in this book). In this chapter, ten decisions from seven Norwegian district courts ${ }^{1}$ will serve as examples of how human rights and legal criteria are relevant to professional practice in emergency cases. It will be discussed whether there is something to learn for professionals working in child protection from the way the courts argue and justify their decisions. ${ }^{2}$

Emergency decisions have to be made within a short period of time, based on alarming, although limited, information about the child's care situation resulting in an urgent need for the child to be protected. It follows from the nature of such placements that they do not meet the normal standards of the rule of law. The right to information, contradiction, careful pre-investigation and collection of all relevant data, informing and hearing the child, are in many cases not possible to comply with. These decisions shed light on how fundamental contradicting interests are being considered and balanced by the courts. How to safeguard the parent's procedural rights and the right to proportionate measures on the one hand, and at the same time secure the child's needs and right to effective protection against violence, abuse and other forms of neglect on the other, are crucial in these cases (see Baugerud and Melinder 2012; Melinder et al. 2013; Storhaug and Kojan 2017).

Human rights and national regulations limit the discretionary power of child protection workers, judges and other decision-making professionals by formulating legal standards, criteria, principals and other kinds of provisions that on the one hand cannot be violated, but on the other hand can be subject to interpretation. This chapter will show and discuss how human rights interact with legal criteria in national law and case facts in child protection emergency cases. The ten cases analysed here are selected from seven Norwegian district courts. In law research, case law can serve both as a relevant legal source of interpretation, and as empirical material. I will use it in both ways, to reveal how discretionary power is performed within the borders of the law, and how professional practice can be guided by fundamental human rights principles. 


\section{The Relevance of Human Rights to Professional Practice in Emergency Cases}

As the Committee of the Rights of the Child is not empowered to make legally binding decisions for the member states, we must turn to the European Court of Human Rights (henceforth 'European Court') to study relevant case law which imposes legal obligations on local social welfare authorities in Europe. In the decisions from the European Court, the Court now regularly refers to the CRC in serious cases of child abuse and neglect, strengthening a child rights perspective and the position of the CRC in its own case law.

The European Convention on Human Rights (ECHR) Article 8(1) states that everyone has the right to respect for his private life and family life. In connection with child abuse and maltreatment, the European Court has developed an extensive case law during the last 20 years. Many of the cases have been initiated by parents claiming their right to family life violated by care order decisions, forced adoption or denial of visitation rights. Some of the cases have been brought into court by the (now adult) children, claiming their right to protection and private life has been violated by non-intervention during their childhood, despite public authorities' knowledge of ongoing child abuse and neglect in their families. The European Court has developed a dynamic interpretation of the term private life in ECHR Article 8, often in conjunction with Article 3 which protects against torture and inhuman and degrading treatment. According to the case law, the notion of private life contents the obligation to secure the child's right to protection of his or her moral and physical integrity.

ECHR Article 8(2) regulates the criteria for intervention in private and family life. First, interference in private or family life can only take place in accordance with the law, which reflects the principle of legality ${ }^{3}$; the need for a specific legal basis in law for the interfering measure. Second, interference can only take place if it is necessary in a democratic society for the protection of the rights and freedoms of others, that is, in this case: the protection of children's life, health and development. This 
reflects the principle of proportionality. Alternative and less intrusive measures must have been considered or carried out.

The ECHR case law reveals the fine balance between the child's and his or her parent's mutual interest in protecting their family life, and the specific interests of the child to be protected from a harmful family life when necessary. As stated in the case Adele Johansen vs Norway 1996, parents 'cannot be entitled under Article 8 of the Convention to have such measures taken as would harm the child's health and development' (see Stang 2015).

In cases concerning child abuse and neglect, the European Court repeatedly underlines the obligations of public authorities to secure effective protection of children, or other vulnerable persons, who are exposed to such ill-treatment committed by parents or other care persons. ${ }^{4}$ It follows from ECHR Article 8 case law, and CRC Article 19, that public authorities must ensure that, upon a discovery of child abuse or neglect, immediate steps will be taken to protect the health and welfare of the abused or neglected child as well as that of any other child under the same care who may be in danger of abuse or neglect (Detrick 1999; Sandberg, Chap. 2 in this book). ${ }^{5}$ Emergency placement is one of the relevant measures that meets the obligation set forward in Article $19 .{ }^{6}$

\section{National Regulation of Interim Orders in Emergencies}

The Norwegian Child Welfare Act (CWA) of 1992 has a specific provision for emergency cases. Section 4-6 (2) states that if there is a risk that a child will suffer material harm by remaining at home, the head of the child welfare administration or the prosecuting authority may immediately make an interim care order without the consent of the parents. ${ }^{7}$ The emergency order must immediately after execution be sent to the County Board for judicial control (see note 6). The order must be approved by the Board Chair as soon as possible, and preferably within 48 hours after receipt. Brief grounds shall be given for the decision. The decision from the County Board might be appealed to the District Court for review. 
Section 4-6 represents an exception from the main legal proceedings in cases of coercive child protection measures. Ordinary proceedings such as a careful three-month investigation, implementing of home-based preventive measures, voluntary measures, hearing the child and documenting the child's own viewpoints, hearing the parents and witness examinations will not be systematically implemented in emergency situations. In these cases, the Parliament has taken a stand by prioritizing the child's right to protection against serious harm over the procedural rights of the parents and the child. The provision of emergency orders is designed in a way that 'downscales' the ordinary safeguarding rule-of-law procedures to facilitate immediate action to protect the child. The European Court has accepted that standpoint in emergency cases. In K. and T. vs Finland 1994, the Court stated that

when an emergency care order has to be made, it may not always be possible, because of the urgency of the situation, to associate in the decisionmaking process those having custody of the child. Nor ... may it even be desirable, even if possible, to do so if those having custody of the child are seen as the source of an immediate threat to the child, since giving them prior warning would be liable to deprive the measure of its effectiveness. ${ }^{8}$

In the K. and T. vs Finland decision the European Court supports the similar principles and child rights-based approach as expressed in CRC Article 19 and in the CRC Committee's General Comment on protection from corporal punishment (cf. Sandberg, Chap. 2 in this book).

However, the fact that the child will suffer harm does not qualify for emergency interventions if the harm does not reach a certain level (material; serious) and the risk situation is urgent. This follows from ECHR Article 8(2): The intervention must be absolutely necessary. General neglect will, as such, normally not qualify for emergency placements. As stated in K. and T. vs Finland, 'The authorities had known about the forthcoming birth for months in advance and were well aware of K.'s mental problems [schizophrenia, psychosis], so that the situation was not an emergency in the sense of being unforeseen." 


\section{Court Review of County Board Decisions in Emergency Cases}

In Norway, there has been a remarkable increase in all kinds of County Board decisions brought to court through appeal (Viblemo et al. 2015). ${ }^{10}$ The share of emergency decisions has increased from 5 per cent in 2008 to 16 per cent in 2013. Quite a large portion of the County Board emergency decisions are being approved by the courts, however, for instance 75 per cent in 2013.

Below, I will describe the kind of situations that lead to emergency placements, and discuss how legal criteria, human rights principles and case facts interact. I will use Norwegian case law as an example of challenges and practices that are most likely to be found in other countries as well. Despite the relatively short presentation of the facts in the Court decisions, they give important information. I will present the cases from the following categories of what emerges as main reasons for the emergency placements: violence, sexual abuse, drug abuse, psychological disorders, risk of abduction and other forms of neglect. In several cases more than one of these factors are present. ${ }^{11}$

\subsection{Violence}

The first case is from Romerike District Court in 2011, concerning three children aged ten, eight and six. The CPS had been in contact with the family since the first child was born. The father had custody for the children because of the mother's mental problems. The eldest boy told CPS that he was beaten by his father each time he did something wrong, and expressed that he was scared of his father. The boy had told his mother that he wanted to kill himself. The mother went to their father's place, a conflict situation developed, and an emergency placement was carried out. All three children were placed in family foster homes with their aunts and their families, and they all seemed to settle down well there. The Court assessed whether the children would suffer serious harm by living with their father, and concluded that such a risk was clearly present. The 
Court also stressed that preventive, voluntary measures had been tried out for a long time, without any significant effect on the children.

In a case from Oslo District Court in 2013 the Court concluded that the criteria for emergency placement of an eight-year-old boy were not met, despite descriptions of neglect and violence from their mother, given by his sister. She had explained that her mother was pulling her hair, beating her, threatening and verbally harassing her. She had told CPS that she spent much time alone at evenings and nights, caring for her younger brother. She also mentioned that her mother took her shoplifting. The younger brother had been witnessing his mother exposing his sister to violence. CPS describe the boy as a vulnerable and insecure child who struggled at school, socially as well as educationally, and showed antisocial behaviour.

The Court underlined the legal criterium 'suffer material harm'; that there is a high threshold for taking a child out-of-home by an emergency placement. Long-lasting neglect is not enough; in such a case ordinary proceedings for a care order would be the proper choice. The boy himself stated, through his spokesperson, that he still would like to live with his mother, that he was fine with her, and if he could not live with her, he wanted to see her Friday, Saturday, Sunday and Monday. Thus the Court could not find that the boy would be exposed to serious harm by staying at home, and that the emergency decision should cease.

These two cases illustrate how long-lasting neglect would typically not reach the level of an emergency unless a situation occurs where the child is proven to be in risk of serious harm, as it did in the first case. There is reason to believe that in the last case, the boy's own and clear views had a major impact on the decision as well. But there is a limit to how serious the long-lasting situation can be before immediate action is required. Where children are living with ongoing, severe maltreatment, sexual abuse or severe drug abuse, public authorities have a clear duty to protect the child immediately and prevent both the actual child and other family members from being exposed to serious risk and harm, by reporting the case to the police, the CPS or otherwise. That duty follows both from CRC Article 19 and ECHR case law, as well as from national regulation on the duty of disclosure. ${ }^{12}$ 


\subsection{Sexual Abuse}

A decision from Eiker, Modum and Sigdal District Court from 2013 concerned an eight-year-old boy. The parents had a custody conflict going on, and the Court of Appeals had awarded custody to the father three years before the District Court decision. The mother had access rights under supervision. Despite detailed descriptions of sexual abuse over time, none of the psychological experts appointed by the District Court nor the Appeals Court had been able to conclude as to any present risk of sexual abuse. Instead, they were of the opinion that it was the mother's strong focus on the issue of abuse that enabled the boy to maintain the story over time. At several occasions, over several years, the boy had told both his mother, the police and CPS about sexual abuse from his father. The police had dismissed the case. Psychological experts had proposed alternative theories to explain the boy's allegations of abuse. After having watched a film with his class at school about sexual abuse, the boy told a teacher 'daddy is doing to me what we saw in the film', and said that he did not want to go home, that he was scared of his dad. CPS effected an emergency placement on the same day, and moved the boy to his mother. Before the Court, CPS referred to the human rights principle of the best interests of the child, and to the principle of proportionality. In its decision, the Court underlined the strict legal criteria in the CWA, and stressed the principle of proportionality as well. Nevertheless, the Court did not agree with earlier court decisions that the boy's statements of sexual abuse derived from his mother's manipulation, and found the boy credible. The Court stated that there was a qualified risk that the boy actually was exposed to abuse from his father, and upheld the emergency care order.

This case is an example of how hard it often is to prove sufficient probability of sexual abuse. This might also be one of the reasons why CPS rarely argue solely with sexual abuse in cases with ordinary care orders. CPS rather tend to prove general neglect, with abuse as a part of this. In cases of physical violence, there might often be other witnesses or supplementing information to the child's own testimony. It is characteristic for sexual abuse that there is a total lack of other evidence than the child's 
own statement, which also underlines the importance of child interviews being carried out according to the law, the ethical guidelines and professional conduct for such conversations. The time pressure in emergency situations does not always permit such interviews.

\subsection{Drug Abuse}

In a case from Sarpsborg District Court 2008, a three-year-old boy was taken into emergency care after the mother was arrested twice and taken into custody because of retention of a large quantum of amphetamine. Both parents were long-time drug abusers, but the mother had managed to maintain a job and keep the abuse hidden from family and working colleagues. The mother temporarily placed the boy with his two uncles and their wives. Just before the mother was released from custody, CPS decided to place the boy in a foster home. Despite the preventive measures that had already been tried, the mother did not prove able to cut contact with the criminal environment of which she was a part, and thus was not able to protect her son from being exposed to criminals and drug abusers who came to their home. In this case, and despite the huge challenges faced by the mother and the negative consequences for her son, the Court concluded that the emergency provision did not apply. The Court agreed with CPS that the care situation could lead to a risk of harming the boy, but not as seriously as required in the law. The boy was described as a well-functioning three year old with a strong and close attachment to his mother. The Court also considered the risk of harm by breaking these bonds. The Court upheld that voluntary preventive measures were likely to minimize the risk of harm to an acceptable level.

The Court did not discuss what an 'acceptable level of risk' actually implies, but this case too shows the importance of a present incident or a more critical situation that clearly differs from more general long-lasting neglect, to meet the criteria for emergency placement instead of an ordinary care order. The fact that the boy was well functioning with a close attachment to his mother was probably important, in the light of the consequences of emergency placements often lasting for a longer period 
of time with very little or no contact between the child and his or her parents. The best-interest principle turned into a 'principle of minor harm'.

\subsection{Psychological Disorders}

In a case from Alstahaug District Court 2011, the emergency order was refused because the criteria in the CWA were not met. The nine-year-old boy in this case had special medical and educational needs. He had shown challenging behaviour at school as well, and his temper was described as 'explosive'. His mother was exhausted and depressed, and could not manage ordinary tasks in the household like washing, dishwashing and cleaning, nor the upbringing of her son who required special attention and care. In a meeting at the CPS office, the mother got so upset she left the meeting. That incident motivated CPS to carry out an emergency placement.

In line with case law, the Court underlines the high threshold and strict criteria for emergency orders. The Court decided not to uphold the order, as it had not been proven that the boy would suffer serious harm by staying at home until the ordinary care order proceedings could start. The Court noted that CPS had failed to make new assessments of the mother's care abilities, nor offered any preventive measures during the period from the emergency placement to the beginning of the Court proceedings.

In a case from Oslo District Court 2009 a seven-year-old girl was taken into emergency care because of the mother's severe psychological problems (acute psychosis) and general neglect. The Court underlined the strict criteria for emergency placements, and that the situation for the child had to be critical. The Court found that there was a serious risk for the child if she was to stay with her mother, and moved the child to a secret address. The mother believed that her daughter was exposed to sexual abuse by the father and by people at school, but the allegations were viewed by the medical experts and the Court as false-as expressions of paranoid delusions - despite the child's descriptions of her father 'using the finger' on her, in the police interview. The Court further concluded that preventive, voluntary measures would not be sufficient to secure the child the care 
she needed, and would not protect the child from the mother's serious delusions.

As with the two cases of violence, these two cases of psychological problems represent the demarcation line between emergency situations due to the level of harm, and 'ordinary' neglect that is harmful, but not that harmful. If a child's care situation makes it acceptable to wait for ordinary care order proceedings, which would take a couple of more weeks, maybe months, to prepare, that would be preferable in the light of the rule-of-law principles; proper investigation, hearing the child and the parents, mapping the child's and parent's network and capacities, and trying out assisting measures.

\subsection{Risk of Abduction}

In some cases, the risk of abduction or harming the child might constitute a legal basis for an emergency placement. In a case from Gjøvik District Court 2009 that was the issue, but the Court overruled the County Board decision. Three children of eight, seven and five were placed at a secret address. One of the children had told a teacher that the family was to move to another country during the autumn vacation 'because then we will get rid of Child Protection Services'. There had been a concern for the care situation during a long period of time, and several notifications had reached the CPS from different professionals. However, the Court did not find that CPS had sufficiently proven that there was a current, concrete and obvious risk of the mother taking the children out of the country.

In another case, from Bergen District Court 2014, the risk for abduction led to an emergency care order decision for three children aged nine, six and two. The father had taken the two oldest children to Sri Lanka, and returned alone two months later. The children came back to Norway after 11 months, and told about violent experiences, sexual abuse, threats and physical punishment while staying with their aunt and uncle in Sri Lanka. The Court, though, concluded that it did not find a real risk for abduction at the time of the Court proceedings. The Court did, in opposite to the County Board, not find it proven that the children had been 
traumatized or had changed behaviour after their stay in Sri Lanka. There were no reports stating that as a fact, or alleging other forms of maltreatment or serious neglect. The children were described as happy and secure during the visitation time with their father, and they had also expressed a wish to see their father. The Court did not share the views of CPS that the mother was incapable of protecting her children, and underlined that the mother had handled the conflicts between the parents in a good manner and with regard to the best interests of the children. The Court concluded that no elements of immediate harm were to be identified in the case, and that the emergency decision had to cease.

These two cases show how CPS have a challenge proving that the risk criteria are met by the facts of the cases, when the Court makes a hereand-now assessment of the risk involved. In the last case, the Court highlighted the children's behaviour towards their father, and that they expressed a wish to see him.

\subsection{Neglect of Newborn Babies}

The case from Gjøvik District Court 2012 concerns the care situation for a baby boy. The baby had been taken to hospital by the parents because he was dehydrated and had lost weight since birth, and needed immediate medical aid. The hospital delivered a notification of concern to CPS, on the basis of lack of fundamental parental abilities. The father was described as passive towards the child; the mother as over-focused on her own situation and health problems. She was later diagnosed with psychosis and transferred to the emergency medical ward. Parental assistance and guidance were offered by CPS, but the situation for the baby was considered to be so serious that an emergency placement was carried out. The District Court found that the baby had been exposed to serious neglect the two first weeks of his life to such a degree that the CPS leader was not sure it would be possible to drive him from one place to another after the care-order decision, due to his state of health. The Court concluded that the boy would face serious harm if he was not immediately placed elsewhere. 
In a case from Sarpsborg District Court 2011 a premature baby boy was placed immediately after birth. Concern for the baby was already expressed during his mother's pregnancy, as the parents did not seem to fully understand their future responsibility as parents, and showed little insight into a newborn child's mental, emotional or physical needs. Further, they did not seem to understand how to act in order to protect the baby from physical harm and accidents. After one month at a family centre, the parents wanted to end the counselling and leave the centre. As CPS feared for the baby's life and health, and considered that the baby needed 24 hours' supervision, the CPS made an emergency decision to prevent the parents from taking the baby with them when they left the family centre. The Court accepted the decision and argued that the baby's special needs as premature and particular vulnerability made special demands on the parents. The Court agreed that the terms 'serious' and 'risk' must be interpreted with regard to the child's young age and vulnerability. The Court underlined that other, less interfering measures had been considered and rejected as not sufficient to safeguard the child's health and development.

The first case shows how fundamental and serious neglect and emotional maltreatment can be life-threatening towards a baby and rather quickly turn into an emergency situation. In this case, there was no time to wait for ordinary care-order proceedings. In both cases, the child's very young age and state of health had an important impact on the risk assessment and might have lowered the threshold for an emergency order. On the other hand, taking a baby into emergency care is a harsh measure towards the parents, but the child's health condition makes the measure proportional. The latter is important in the light of the right to family life. In K. and T. vs Finland, the European Court outlines that

when such a drastic measure for the mother, depriving her totally of her new-born child immediately on birth, was contemplated, it was incumbent on the competent national authorities to examine whether some less intrusive interference into family life, at such a critical point in the lives of the parents and child, was not possible. ${ }^{13}$ 


\section{Lessons Learned from Norwegian Case Law}

The case law discussed here shows that the children involved are often finding themselves in very serious situations, as they risk being exposed to their parents' violence, drug abuse, psychological problems, sexual abuse, abduction or other forms of neglect and maltreatment. The case facts give a picture of emergency measures being used first and foremost in cases of grave neglect and abuse. This is an important perspective to consider. In some of the cases, it might even be difficult to see an obvious explanation for letting the child remain in a clearly harmful home situation, only to wait for ordinary care-order proceedings to be exercised. What level of harm or neglect is acceptable for a child to live with for another couple of weeks or months? The quite brief presentations of the facts and assessments in the Court decisions do not give necessary and complementary information to sufficiently review the assessments of the child's best interests, but it still is an important, and quite uncomfortable, question to ask.

In several of the cases, the risk assessments seem inadequate and incomplete according to general quality standards, but do not follow any common national protocol. The wide margin of discretion in these cases combined with the lack of time to make thorough investigations, may increase the risk of making wrong decisions. That may be a necessary price to pay for being able to intervene on short notice to protect the child involved.

The case law shows that the criteria in the CWA are being strictly interpreted: there must exist a real, present risk for the child's health and development, if emergency placements are to be judged the right measure. If the situation is harmful, but has not yet developed into critical, the child and the family might still be better taken care of through ordinary careorder proceedings. In some cases even voluntary measures like family counselling might work to solve the main problems.

One interesting aspect of the Court decisions is the lack of a broader best-interest assessment in several decisions. The Court's assessments seem to focus mainly on the judicial control of legal criteria, like the level of risk and harm, whether the situation is an emergency, and whether assisting and less intrusive measures have been tried out. Only a few of the 
court decisions contain a thorough assessment of the best interests of the child, which is a professional duty according to the CWA, the CRC and ECHR case law as well as the Norwegian Constitution. On the other hand, the child's own views are being highlighted in many of the cases, and given due, and sometimes decisive, weight.

Another aspect with the court decisions is the tendency to consider or carry out family placements in emergency cases. Family- or network-based placements would in some cases reduce the stress for both the child and the parents, and enable the maintenance of bonds between the child and family members other than the parents.

As follows from the review of case law, several types of mistakes might cause disapproval in the Court, whether this is in the child's best interests or not. CPS might not be able to argue sufficiently well for the necessity of the placement, or that preventive measures have been proven insufficient. CPS might have interpreted or used the CWA provision in a wrong way/on wrong terms, or is not able to prove that the child is living in a situation of real, present, qualified risk.

One lesson learned from the case law may be that child protection workers have to pay due attention to the legal criteria for coercive measures and interventions. They need to convince the County Board or the courts why and how the child's situation corresponds to the risk level in the relevant emergency provision. Child welfare workers also need to explain why less intrusive measures would not be sufficient to prevent serious harm to the child, and consider the positive and negative impact of emergency placement on the parents' and the child's situation. Thorough and well-founded best-interests assessments are supposed to be developed and carried out, and risk assessments should be improved, including how the child's age, vulnerability, own viewpoints and state of health influence the risk level.

Nevertheless, the considerations and interpretations of legal criteria, assessments of facts, the guiding principles and human rights, all involve elements of professional discretion. A variety of relevant aspects are to be carefully balanced; judicial, psychological, cultural and medical aspects for instance. The case law reveals a blurred borderline between 'serious' and 'less serious' harm; between 'critical' and 'not so critical' neglect. The most complex assessment is that of the best interests of the child, or rather 
of the least detrimental alternative. The individual traits of the case and the needs of the child involved will be crucial.

\section{How Human Rights Can Guide Professional Practice in Emergency Cases}

Emergency placements represent an extreme intervention into the right of family life. The national authorities - the CPS, the County Board and the courts - must not exceed their margin of appreciation. National authorities must exercise their discretionary power within the borders of the law. The CPS and the County Boards have to prove why and how the emergency placement is necessary to prevent the child from being exposed to serious harm. The European Court underlined in K. and T. vs Finland that national authorities must 'establish that a careful assessment of the impact of the proposed care measure on the [parents] and the children, as well as the possible alternatives to taking the children into public care' are carried out prior to the implementation of such a measure. ${ }^{14}$ The European Court sets an ambitious standard here, in the light of the nature of emergency situations and the need for quick action, that does not fit completely well with the Court's own case law, highlighting the duty of the member states to effectively protect children living with serious neglect and abuse.

As a main rule, less interfering alternatives should be considered or tried out prior to an emergency placement, or at least as a part of the judicial control. Important questions are when and for how long preventive measures and network-based interventions should be tried out without risking further harm to the child's health and development. The human rights obligations to effectively protect children exposed to real, present risk for serious harm because of violence, sexual abuse or other forms of serious neglect, must be implemented as well. A thorough assessment of the child's best interests should provide an answer in each case.

Human rights conventions represent the external, judicial limits for the local authorities' investigations, measures, proceedings, and for how they balance the different interests of the parties involved, as well as the single elements of the case facts, while exercising their discretionary 
power. Like any other public authority, social and child protection services must manage their professional power within the framework of human rights legislation, national law and fundamental principles.

\section{Conclusion}

The complex tension between the strong interventional nature and stressful character of emergency placements and the necessity of legal regulations which enable such placements to secure effective protection for children at risk, reflects contradicting human rights. The right to respect for family life, the principle of proportionality, the best-interest principle and the right for the individual child to immediate protection from serious and present risks to the child's health and development, do all apply in emergency cases. In balancing all these rights and interests, it follows from the CRC and the ECHR case law that the best interests of the child shall be a paramount consideration, and that public authorities hold a duty to protect children and other vulnerable individuals against harmful experiences that threaten their private life, their physical and psychological integrity, or that expose them to inhuman or degrading treatment. For children in particular, serious violations of their integrity impose a threat to their fundamental right to life and development.

\section{Notes}

1. These are Oslo District Court, Bergen District Court, Sarpsborg District Court, Romerike District Court, Gjøvik District Court, Alstadhaug District Court, and Eiker, Modum and Sigdal District Court.

2. Only a few district court decisions are published in the Norwegian judicial database Lovdata.no. No cases concerning emergency orders from the Supreme Court or the Courts of Appeals were found in this database, making district court decisions a relevant source of law.

3. In Norwegian: legalitetsprinsippet. The principle has been developed by the Supreme Court, and has obtained constitutional status in national law.

4. See e.g. A. vs UK 1998, paras 20-24. See also Z. and Others vs UK 2001. 
5. The term 'neglect' in CRC Article 19 includes physical neglect as well as psychological and emotional neglect.

6. The Norwegian child protection system consists of the municipal Child Protection Services (CPS), the County Board of Child Protection and Social Affairs (henceforth 'the County Board'), the Office for Children, Youth, and Family Affairs (Bufetat) with institution and foster home services. The CPS investigate referrals and decide and implement all voluntary preventive measures, as well as interim emergency care orders. The County Board is a regional, administrative court-like body with similar civil procedural regulations as a district court, and decides all coercive measures.

7. https:/www.regjeringen.no/en/dokumenter/the-child-welfare-act/ id $448398 /$.

8. K. and T. vs Finland 1994, para. 166

9. K. and T. vs Finland 1994, para. 168.

10. Out of a total of 3492 claims in 2013, 902 of them concerned access rights for parents, 631 claims were concerned with care-order decisions, 491 with foster care placements, 483 with supervision and 317 with emergency placements by CWA section 4-6 (2).

11. I also did a search in the database for published emergency care order decisions and complaints from the County Boards. Out of 86 published emergency order decisions and complaints in 2008-2016, the summaries show that main reasons for emergency placement were: violence (21 cases), sexual abuse (4 cases), drug abuse (16 cases), psychological disorders/problems (7 cases), risk of abduction (2 cases), other forms of neglect ( 21 cases), not specified in the summary ( 15 cases).

12. See e.g. A. vs UK 1998, paras 20-24. See also Z. and Others vs UK 2001. The European Court has based its case law on these two cases in later decisions.

13. K. and T. vs Finland 1994, para. 168.

14. K. and T. vs Finland 1994, para. 168 i.f.

\section{References}

Baugerud, G. A., \& Melinder, A. (2012). Maltreated children's memory of stressful removals from their biological parents. Applied Cognitive Psychology, 26(2), 261-270. 
Detrick, S. (1999). A commentary on the United Nations convention on the rights of the child. Leiden: Martinus Nijhoff Publishers.

Gilbert, N., Parton, N., \& Skivenes, M. (2011). Child protection systems: International trends and orientations. Oxford: Oxford University Press.

Stang, E. G. (2015). The child's right to protection of family life and private life. In S. Mahmoudi, P. Leviner, A. Kaldal, \& K. Lainpelto (Eds.), Child-friendly justice: A quarter of a century of the UN Convention on the Rights of the Child. Leiden: Brill/Nijoff.

Melinder, A., Baugerud, G. A., Ovenstad, K. S., \& Goodman, G. S. (2013). Children's memories of removal: A test of attachment theory. Journal of Traumatic Stress, 26(1), 125-133.

Sandberg, K. (2018). Children's right to protection under the CRC. In A. FalchEriksen \& E. Backe-Hansen (Eds.), Human rights in child protection. Implications for professional practice and policy. London: Palgrave Macmillan. Storhaug, A. S., \& Kojan, B. H. (2017). Emergency out-of-home placements in Norway: Parents' experiences. Child \& Family Social Work, 22(4), 1407-1414. Viblemo, T., Gleinsvik, A., Meltevik, S., \& Vestergaard, M. (2015). Organisering, effektivitet og rettssikkerhet: Evaluering av Fylkesnemndene for barnevern og sosiale saker. Stavanger: Oxford Research.

Open Access This chapter is licensed under the terms of the Creative Commons Attribution 4.0 International License (http://creativecommons.org/ licenses/by/4.0/), which permits use, sharing, adaptation, distribution and reproduction in any medium or format, as long as you give appropriate credit to the original author(s) and the source, provide a link to the Creative Commons license and indicate if changes were made.

The images or other third party material in this chapter are included in the chapter's Creative Commons license, unless indicated otherwise in a credit line to the material. If material is not included in the chapter's Creative Commons license and your intended use is not permitted by statutory regulation or exceeds the permitted use, you will need to obtain permission directly from the copyright holder.

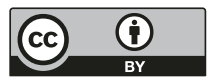

